NBER WORKING PAPER SERIES

\title{
LINKAGE OF TRADABLE PERMIT SYSTEMS IN INTERNATIONAL CLIMATE POLICY ARCHITECTURE
}

\author{
Judson Jaffe \\ Robert N. Stavins \\ Working Paper 14432 \\ http://www.nber.org/papers/w14432 \\ NATIONAL BUREAU OF ECONOMIC RESEARCH \\ 1050 Massachusetts Avenue \\ Cambridge, MA 02138 \\ October 2008
}

This paper, prepared for the Harvard Project on International Climate Agreements, draws, in part, on Jaffe and Stavins (2007), which built upon previous studies by Haites and Mullins (2001), Baron and Bygrave (2002), Blyth and Bosi (2004), Baron and Philibert (2005), Ellis and Tirpak (2006), and Kruger et al. (2007). Exceptionally valuable research assistance was provided by Matthew Ranson, and our research benefitted greatly from communications with Joseph Aldy, Scott Barrett, Denny Ellerman, Robert Keohane, and David Victor. The authors are grateful to Joseph Aldy for comments on a previous version of the manuscript, but all remaining errors are our own. The views expressed herein are those of the author(s) and do not necessarily reflect the views of the National Bureau of Economic Research.

NBER working papers are circulated for discussion and comment purposes. They have not been peerreviewed or been subject to the review by the NBER Board of Directors that accompanies official NBER publications.

(C) 2008 by Judson Jaffe and Robert N. Stavins. All rights reserved. Short sections of text, not to exceed two paragraphs, may be quoted without explicit permission provided that full credit, including $\odot$ notice, is given to the source. 
Linkage of Tradable Permit Systems in International Climate Policy Architecture

Judson Jaffe and Robert N. Stavins

NBER Working Paper No. 14432

October 2008

JEL No. F50,Q20,Q40,Q50

\begin{abstract}
$\underline{\text { ABSTRACT }}$
Cap-and-trade systems have emerged as the preferred national and regional instrument for reducing emissions of greenhouse gases throughout the industrialized world, and the Clean Development Mechanism — an international emission-reduction-credit system — has developed a substantial constituency, despite some concerns about its performance. Because linkage between tradable permit systems can reduce compliance costs and improve market liquidity, there is great interest in linking cap-and-trade systems to each other, as well as to the CDM and other credit systems. We examine the benefits and concerns associated with various types of linkages, and analyze the near-term and long-term role that linkage may play in a future international climate policy architecture. In particular, we evaluate linkage in three potential roles: as an independent bottom-up architecture, as a step in the evolution of a top-down architecture, and as an ongoing element of a larger climate policy agreement. We also assess how the policy elements of climate negotiations can facilitate or impede linkages. Our analysis throughout is both positive and normative.
\end{abstract}

Judson Jaffe

Analysis Group, Inc.

111 Huntington Avenue, 10th Floor

Boston, MA 02199

jjaffe@ analysisgroup.com

Robert N. Stavins

JFK School of Government

Harvard University

79 JFK Street

Cambridge, MA 02138

and NBER

robert_stavins@harvard.edu 


\title{
Linkage of Tradable Permit Systems IN International Climate Policy Architecture
}

\author{
Judson Jaffe \\ Robert N. Stavins ${ }^{*}$

\section{Introduction}

As the nations of the world consider alternative international climate policy architectures for the post-2012 period, tradable permit systems are emerging as a preferred domestic instrument for reducing greenhouse gas (GHG) emissions. The two most significant institutions for reducing GHG emissions implemented to date — the European Union Emissions Trading Scheme (EU ETS) and the Clean Development Mechanism (CDM) - are tradable permit systems. Furthermore, tradable permit systems are being considered as the primary policy instrument for reducing GHG emissions in Australia, Canada, Japan, and the United States, among other countries.

Due to the increasingly likely prospect of a world with multiple tradable permit systems, attention has focused on how and whether to link these systems. Linking occurs when a tradable permit system's regulatory authority allows regulated entities to use emission allowances or emission reduction credits from another system in order to meet their domestic compliance obligations. ${ }^{1}$ These entities can then take advantage of the cost savings from international trade: just as allowance trading within a tradable permit system allows higher-cost emission reductions to be replaced by lower-cost reductions within that system, trading across systems allows higher-cost reductions to be replaced by lower-cost reductions from a different system. These cost savings create significant incentives for regulatory authorities to link tradable permit systems, but there are also some reasonable concerns about linkage, such as impacts on global emissions and on national control over allowance prices.

We examine the benefits and concerns associated with international linkage, and analyze how linkage may become part — possibly a central part — of the post-2012 international climate policy architecture. Section 2 introduces the two general categories of tradable permit systems: cap-and-trade and emission-reduction-credit systems. Section 3 reviews existing and proposed GHG tradable permit systems. Section 4 describes the major types of linkages and provides examples of existing linkages. Section 5 examines the general implications of linkage, including potential benefits and concerns.

\footnotetext{
*Jaffe is Vice President, Analysis Group; and Stavins is the Albert Pratt Professor of Business and Government at the John F. Kennedy School of Government, Harvard University, University Fellow of Resources for the Future, and Research Associate of the National Bureau of Economic Research. This paper draws, in part, on Jaffe and Stavins (2007), which built upon previous studies by Haites and Mullins (2001), Baron and Bygrave (2002), Blyth and Bosi (2004), Baron and Philibert (2005), Ellis and Tirpak (2006), and Kruger et al. (2007). Exceptionally valuable research assistance was provided by Matthew Ranson, and our research benefitted greatly from communications with Joseph Aldy, Scott Barrett, Denny Ellerman, Robert Keohane, and David Victor. The authors are grateful to Joseph Aldy for comments on a previous version of the manuscript, but all remaining errors are our own.

${ }^{1}$ Such linkage of domestic tradable permit systems is completely different from the state-to-state trading envisaged under Article 17 of the Kyoto Protocol, whereby signatories to the Protocol can trade their "assigned amounts."
} 
Section 6 discusses the role that linking of tradable permit systems may play in future international policy architectures, both in the near-term and in the long-term. Section 7 provides an evaluation of linkage in three specific roles: as an independent bottom-up architecture, as a step in the evolution of a top-down architecture, and as an element of a larger policy architecture. In section 8 , we examine how the policy elements of near-term climate negotiations could affect the prospects for linkage. Finally, section 9 concludes.

\section{Categories of Tradable Permit Systems}

Because the implications of linking depend on the type of tradable permit systems that are linked, it is essential to distinguish between two categories of systems: cap-and-trade and emissionreduction-credit systems.

\subsection{Cap-and-Trade Systems}

A cap-and-trade system constrains the aggregate emissions of regulated sources by creating a limited number of tradable emission allowances, which emission sources are required to secure and surrender in number equal to their emissions. Faced with the choice between surrendering an allowance or reducing their emissions, firms will choose whichever option is less expensive. As long as trading costs are low and allowance markets are sufficiently competitive, trading will lead firms to put allowances to their highest-valued use - that is, covering those emissions that are most costly to reduce — regardless of how the allowances are initially distributed (Stavins 1995; Hahn 1984). Conversely, the opportunity to trade allowances ensures that the emissions reductions undertaken to meet the cap are those that are the least costly to achieve.

In developing a cap-and-trade system, policymakers must decide on several design elements (Stavins 2008). Policymakers must determine how many allowances they will issue, which defines the system's cap. Policymakers must also determine the scope of the cap's coverage, or what emission sources and types of GHG emissions will be subjected to the overall cap. A related decision regards the system's point of regulation. A cap on energy-related carbon dioxide $\left(\mathrm{CO}_{2}\right)$ emissions can be enforced by requiring fossil fuel suppliers to surrender allowances for the carbon content of their fuel sales ("upstream regulation"), or by requiring final emitters to surrender allowances for their emissions (“downstream regulation").

Policymakers also must determine how to distribute allowances. Allowances can be freely distributed or auctioned, or a combination of the two approaches can be employed. If allowances are freely distributed, there are limitless possible methods for determining who receives them, and how many allowances each recipient receives. Finally, policymakers must decide on several features of the cap-and-trade system relating to monitoring, reporting, and enforcement of compliance.

A key concern in many countries developing mandatory climate policies is uncertainty regarding compliance costs. In the context of a cap-and-trade system, this concern is often expressed as concern about the level and volatility of allowance prices. In response to this concern, much attention has been given to the opportunity to include "cost-containment" measures in cap-and-trade systems, such as 
offset provisions, allowance banking and borrowing, and safety-valve provisions. ${ }^{2}$ An offset provision allows regulated entities to offset some of their emissions with credits from emission reduction measures that are outside the cap-and-trade system's scope of coverage. Banking allows firms to save unused allowances for use in future years. Borrowing allows firms to use allowances that will be issued in future years to demonstrate compliance in an earlier year. Both banking and borrowing allow firms flexibility to shift emission reduction efforts over time to minimize costs.

A safety valve puts an upper bound on the compliance costs that firms will incur by offering them the option of paying a predetermined fee (the safety-valve "trigger price") to purchase additional allowances. In its simplest form, a safety valve introduces a tradeoff between avoiding unexpectedly high costs and achieving a system's emissions target. When a safety valve is exercised, firms' emissions exceed the number of allowances that were initially distributed. However, this tradeoff can be mitigated (or potentially eliminated) through provisions such as reducing subsequent years' caps in response to use of the safety valve (Stavins 2008).

\subsection{Emission-Reduction-Credit Systems}

An emission-reduction-credit system brings about emission reductions by awarding tradable credits for certified emissions reductions. Some programs that are described as credit systems can be quite similar to a cap-and-trade system. ${ }^{3}$ When we refer to credit systems, we are describing systems that have a few key differentiating characteristics. First, participation in the systems is voluntary. Second, the systems serve only as a source of credits that can be used by entities facing compliance obligations in other systems. They do not themselves impose any obligations on entities to hold or surrender credits. Third, the systems grant credits for particular projects based on an estimate of how those projects reduce emissions from some agreed-upon baseline level of what emissions would have been if the projects had not been carried out.

In designing a credit system, policymakers must determine what types of emission sources and actions can be awarded credits. For example, certain emission reduction projects may be excluded from consideration due to concern about the feasibility of measuring results accurately. Also, policymakers must decide on a method for calculating the number of credits that are awarded. These calculations can be performed on a project-by-project basis, or they can be based on standards applied to all projects of a particular type. In either case, it is necessary to estimate what baseline emissions would have been absent the credited action.

\section{Greenhouse Gas Tradable Permit Systems}

Although there are only a limited number of existing GHG tradable permit systems, the list of planned and prospective systems is considerably longer. It is the increasing number and prominence

\footnotetext{
${ }^{2}$ For a discussion of these and other cost-containment proposals, see: Tatsutani and Pizer 2008.

${ }^{3}$ For example, a credit system may set individual emissions limits for firms, and allow them to generate tradable credits if they reduce their emissions below their assigned limit. Such a system would be essentially identical to a cap-and-trade system where each firm is allocated a quantity of allowances that reflects its specific emissions limit.
} 
of such systems, and the economic and political incentives to link them that provide the motivation for our analysis of linkage as a potential element of the post-2012 international policy architecture. Hence, we provide a brief review of some of the major existing, planned, and proposed systems.

\subsection{Cap-and-Trade Systems}

\subsubsection{European Union Emissions Trading Scheme}

The European Union Emissions Trading Scheme (EU ETS) is the world's largest GHG cap-and-trade system. Phase I of the EU ETS, from 2005 to 2007, capped aggregate $\mathrm{CO}_{2}$ emissions from more than 11,000 industrial facilities and electricity generators in 25 European countries (European Commission 2005). Those sources collectively emitted approximately two billion metric tons of $\mathrm{CO}_{2}$ in 2005, about 45 percent of the EU's $\mathrm{CO}_{2}$ emissions (European Commission 2005, 2007b). The EU ETS cap has been tightened for Phase II, which runs from 2008 to 2012. Also, the scope of the EU ETS has been expanded to cover new sources in countries that participated in Phase I, and to include sources in Bulgaria and Romania, which acceded to the EU in 2007. The European Union plans to extend the EU ETS to 2020 (European Commission 2008).

\subsubsection{Norvegian Emissions Trading Systems}

A Norwegian emissions trading system began operation at the same time as the EU ETS. From 2005 to 2007, it covered a relatively small set of industrial sources accounting for just 10 to 15 percent of Norway's GHG emissions (Norwegian Ministry of the Environment 2005). Norway has since agreed to adjust its system to conform to the rules and procedures of the EU ETS, with which it will be linked. These adjustments include broadening the scope of emission sources that are covered, such that Norway's system will cover approximately 40 percent of its GHG emissions (Euractiv.com 2007).

\subsubsection{Japan's Emissions Trading System}

Japan has had a Voluntary Emissions Trading System (JVETS) in operation since April, 2006, but participating facilities have accounted for no more than a few million tons of Japan's annual GHG emissions, which exceeded 1.3 billion metric tons in 2004 (Sudo 2006; Japanese Ministry of the Environment 2006). After considerable national discussion and debate, Prime Minister Yasuo Fukuda announced in June 2008 that the government would employ a cap-and-trade system as its main instrument to achieve ambitious reduction targets of 60 to 80 percent below current levels by 2050 (ABC News 2008). A trial trading period for $\mathrm{CO}_{2}$ emissions is scheduled to begin in October of 2008 (BusinessGreen 2008).

\footnotetext{
${ }^{4}$ For an assessment of the EU ETS as a model of a potential future international climate policy architecture, see the paper prepared by Denny Ellerman for the Harvard Project on International Climate Agreements. For an analysis of the performance of the EU ETS, see the symposium of three articles in the Review of Environmental Economics and Policy, Volume 1, Number 1, Winter 2007.
} 


\subsubsection{Australia's Proposed System}

In 2004, the States and Territories of Australia established the National Emissions Trading Taskforce (NETT) to develop a proposal for a cap-and-trade system, which was released in August 2006 (National Emissions Trading Taskforce 2006). In December 2006, Prime Minister Howard established his Task Group on Emissions Trading, which issued a report in May 2007 proposing a nationwide cap-and-trade system that would have the broadest practicable coverage of Australia's GHG emissions (Australian Prime Ministerial Task Group on Emissions Trading 2007).

With the change in government in December, 2007, Prime Minister Kevin Rudd lent his support for the implementation of a cap-and-trade system by 2010 (and for ratification of the Kyoto Protocol). In July, 2008, the Australian government released a green paper with its detailed plan for a national capand-trade system to reduce $\mathrm{CO}_{2}$ emissions 60 percent below 2000 levels by 2050 (Australian Government 2008). Based upon feedback from stakeholders, the government intends to release a white paper and to draft implementing legislation by the end of 2008.

\subsubsection{Regional Greenhouse Gas Initiative and Other Regional Efforts in the United States}

In 2005, seven northeastern U.S. states agreed to implement the Regional Greenhouse Gas Initiative (RGGI), which three additional northeastern states subsequently joined. ${ }^{5}$ The program is expected to begin in 2009, and would introduce a cap-and-trade system for electricity generators within the ten states. The first auction of RGGI allowances was completed on September 25, 2008. The program is intended to place an aggregate cap on covered generators' emissions equal to nearly 190 million tons of $\mathrm{CO}_{2}$ per year from 2009 to 2014, a level roughly comparable to those generators' recent emissions. From 2015 to 2018, the cap would be reduced by 2.5 percent per year.

In addition to RGGI, other regional and state efforts to limit GHGs in the United States have begun. One of the most prominent has resulted from California's enactment of its Global Warming Solutions Act of 2006, which set a statewide GHG emissions limit for 2020 equal to California's 1990 emissions level. In its June 2008 draft "scoping plan," California's Air Resources Board (2008) included a statewide cap-and-trade system for all energy-related $\mathrm{CO}_{2}$ emissions as one of the key elements of its preliminary recommendations for achieving the 2020 target.

\subsubsection{Proposals for a Federal Cap-and-Trade System in the United States}

Several bills proposing a federal GHG cap-and-trade system were introduced in the 110th U.S. Congress. The proposals differed in many important respects, including the cap's scope of coverage, the level of the cap, and the measures that are proposed to address cost uncertainty. It appears increasingly likely that a meaningful, upstream, economy-wide cap-and-trade system will be adopted by the United States in 2009 or 2010. In 2008, both presidential candidates — Senators John McCain and Barack Obama - expressed enthusiastic support for such an approach.

\footnotetext{
${ }^{5}$ The participants are: Connecticut, Delaware, Maine, Maryland, Massachusetts, New Hampshire, New Jersey, New York, Rhode Island, and Vermont.
} 


\subsubsection{Proposed Canadian System}

The Canadian Government has announced its intention to implement a regulation requiring reductions in the emissions intensity of major stationary sources of GHG emissions in Canada, which together account for about half of Canada's GHG emissions (Environment Canada 2008). Regulated sources would be required to achieve an 18 percent reduction in their emissions intensity from 2006 levels by 2010, and an additional 2 percent reduction in each year thereafter. In meeting their compliance obligations, among other compliance options, regulated sources could rely on emissions trading with other sources that have reduced their emissions intensity by more than the required amount.

\subsection{Emission-Reduction-Credit Systems}

\subsubsection{Clean Development Mechanism}

Established under the Kyoto Protocol, the Clean Development Mechanism (CDM) is the most significant GHG emission-reduction-credit system to-date. Under the CDM, certified emission reductions (CERs) are awarded for voluntary emission reduction projects in developing countries that ratified the Protocol, but are not among the Annex I countries subject to the Protocol's emissions limitation commitments. While CERs can be used by Annex B Parties to the Protocol - the 37 industrialized countries and emerging market economies of central and eastern Europe who took on targets under the Protocol - to meet their emissions commitments, they could also be used for compliance purposes by entities covered by various cap-and-trade systems throughout the world, including systems in countries that are not Parties to the Protocol, such as the United States. ${ }^{6}$

An Executive Board established under the Kyoto Protocol is responsible for supervising the $\mathrm{CDM}$ and for making determinations about the issuance of CERs for particular projects. From project initiation, it can take as long as two or more years to go through that process, and the cost of the process (not including the cost of the actual emission reduction measures) can be substantial (Nigoff 2006; Michaelowa and Jotzo 2005). Nonetheless, as of August 2008, more than 3,000 projects were in the CDM "project pipeline." These projects are expected to generate more than 2.7 billion CERs by the end of 2012, with each CER reflecting emission reductions of one metric ton of carbon dioxide equivalent. The Executive Board had registered more than 1,100 of these projects, expected to yield 1.3 billion CERs by 2012. Projects in China account for 52 percent of the expected CERs from registered projects, India 14 percent, Brazil 9 percent, South Korea 7 percent, and projects in 46 other countries collectively account for the remaining 19 percent (UNFCCC 2008).

\subsubsection{Joint Implementation}

Like the CDM, Joint Implementation (JI) was established as a project-based flexibility mechanism under the Kyoto Protocol. However, unlike the CDM, JI applies to emission reduction projects carried out in an Annex I country (the host country) that has a national emissions target under

\footnotetext{
${ }^{6}$ For example, under certain circumstances (and to a limited extent), regulated entities could use CERs to meet their
} compliance obligations under the RGGI system (RGGI 2007a). 
the Protocol. JI projects generate credits, referred to as emission reduction units (ERUs), that can be used to cover increased emissions in other countries. When these credits are generated, a corresponding reduction is made in the host country's emissions target under the Protocol. This ensures that the use of ERUs to cover increased emissions in another country is, in fact, offset by a net reduction in the host country's emissions.

JI projects will likely produce far fewer credits than the CDM. The Joint Implementation Supervisory Committee began accepting proposals in October 2005 (Pointcarbon 2007). By August 1, 2008, it had received submissions for only 163 projects, accounting for an estimated 280 million tons of $\mathrm{CO}_{2}$-equivalent emission reductions over the five years of the Kyoto Protocol's first commitment period (UNEP Risoe Centre 2008).

\subsubsection{Domestic Offset Programs}

In designing domestic cap-and-trade systems, governments can establish offset programs for creating emission reduction credits that can be used by regulated entities to meet compliance obligations. For example, electricity generators covered by RGGI can use domestic offsets to cover part of their emissions. RGGI has established a set of project types that can be implemented to generate offset credits, as well as standards for determining the number of allowances that projects are awarded (RGGI 2007a). Cap-and-trade systems proposed in Australia, Canada, and the United States also include offset programs.

\section{Types of Linkages}

The type of link that is established has important implications for its effects. Direct linkages between systems can be one-way (unilateral) or two-way (bilateral or multilateral). Also, while direct links between systems can be established only as a result of explicit decisions to do so, direct links can lead to indirect links between systems even absent explicit decisions to link them (Jaffe and Stavins 2007).

\subsection{Direct Linkages}

In order for a direct linkage to be established between two systems, either one or both systems must accept the other's allowances or credits as valid for use in demonstrating compliance in its own system.

\subsubsection{Linkage between a Cap-and-Trade System and Credit System}

In a direct link between a cap-and-trade system and a credit system, the cap-and-trade system chooses to recognize emission reduction credits from the credit system. Because the credit system does not place requirements on entities to surrender credits or allowances, this linkage is necessarily one-way. If the price of credits is lower than the price of emission allowances, then regulated firms in the cap-andtrade system have an incentive to purchase credits. This will reduce the price of allowances in the capand-trade system and increase the price of credits in the credit system until the two prices converge. 


\subsubsection{Linkages between Cap-and-Trade Systems}

Cap-and-trade systems can recognize allowances from other cap-and-trade systems. The resulting linkage can be one-way or two-way, depending on whether the recognition is mutual.

In an unrestricted one-way link in which System A recognizes System B's allowances, if System A's allowance price is higher than System B's, participants in System A will buy allowances from participants in System B, thereby reducing System A's allowance price and increasing System B's price until the prices converge. Such trading will increase emissions in A and decrease emissions in B, as higher cost emission reductions in $\mathrm{A}$ are avoided and replaced by lower cost reductions in $\mathrm{B}$. However, if System A's allowance price is lower than System B's, no trading will result from the one-way link. Hence, a one-way link in which A recognizes B's allowances will ensure that A's allowance price never exceeds B's price.

In a two-way direct link, both cap-and-trade systems recognize each other's allowances, making it possible for allowances to flow in either direction. Two-way links can be bilateral or multilateral. As the result of a two-way linkage, any difference between the systems' allowance prices will lead to sales of allowances from the lower price system to the higher price system until the systems' allowance prices converge at an intermediate level, leading to an increase in emissions in the higher price system and an offsetting reduction in emissions in the lower price system.

If governments place limits on inter-system trading, allowance price convergence may not be complete. A government may limit the quantity of allowances from another system that can be used to demonstrate compliance in its own system. Alternatively, participants in a system may be allowed unrestricted use of another system's allowances, but an "exchange rate" might be applied to their use. Such a requirement might be used to reconcile differences in the denomination of different systems' allowances (e.g., metric tons vs. short tons), to reduce inter-system trading, or to ensure that trading leads to a net reduction in emissions.

\subsection{Indirect Linkages}

Even if neither system recognizes the other's allowances, two systems can become indirectly linked through direct links with a common third system. As a result of trading between each of the two systems and the common system, developments in one of the indirectly linked systems can affect the supply and demand for allowances in the other system. Hence, changes in the allowance price and emissions level in one system can affect the allowance price and emissions level in a system with which it is indirectly linked.

\subsubsection{Indirect Linkages Arising from One-way Links between Multiple Cap-and-trade Systems and a Common Credit System}

Indirect links can be created between two cap-and-trade systems if both have one-way links with a common credit system. As a result of such one-way links, the two indirectly linked systems will compete for credits from the third system. This indirect linkage will reduce the difference between the two cap-and-trade systems' allowance prices, as credits will flow to the system with the higher price. 
In fact, if there is a sufficient supply of credits at a price below the two cap-and-trade system's pre-link allowance prices, prices in the three systems will converge fully.

\subsubsection{Indirect Linkages Arising from Linkages between Cap-and-Trade Systems}

A series of bilateral links among several systems can also create indirect links among those systems. This kind of indirect linkage is identical in its effects to a direct multilateral link among all of the systems involved. For example, if System A has a two-way link with System B, which has a two-way link with System C, then trading will lead allowance prices to converge across all three systems even though $\mathrm{A}$ and $\mathrm{C}$ are not directly linked.

\subsection{Examples of Existing Linkages}

Some linkages have already been established among tradable permit systems for greenhouse gases, reflecting the strong incentives that governments face to establish these connections.

\subsubsection{One-way Linkages}

Through its "Linking Directive" (2004/101/EC), the European Commission has allowed EU ETS participants to use CDM CERs to meet compliance obligations beginning in 2005, and JI ERUs beginning in 2008 (European Commission 2004). The Directive places restrictions on this linkage, however. CERs and ERUs generated from nuclear facilities, land use change, and forestry activities are not recognized, and quantitative limits are placed on the use of CERs and ERUs (European Commission 2007a). ${ }^{7}$ The effects of this linkage are already apparent in secondary markets for CERs, where CER prices have closely tracked Phase II EU ETS allowance prices (Carbonpositive 2007).

In the United States, the Model Rule governing the implementation of the Regional Greenhouse Gas Initiative (RGGI) allows for several types of one-way links. Covered sources may use emission reduction credits from qualified domestic offset projects, subject to quantitative limits that depend on the prevailing RGGI allowance price (RGGI 2007a). At most, no more than 10 percent of a source's emissions can be covered by offsets. When and if the RGGI allowance price exceeds a specific threshold, which increases over time, sources have the additional option to use CERs and allowances from other countries' cap-and-trade systems, such as the EU ETS, in meeting their compliance obligations. $^{8}$ However, sources are still required to cover at least 90 percent of their emissions with RGGI allowances.

\footnotetext{
${ }^{7}$ The European Commission has placed limits on the use of CERs and ERUs in each Member State at a level necessary to ensure that the total use of CERs and ERUs by each Member State — including, but not limited to use in the EU ETS constitutes no more than half of the reductions necessary to meet that Member State's Kyoto target, as modified by the reallocation of its target under the European Union's "bubble." For a description of the method that the European Commission employs to determine these limits, see European Commission (2007a), paragraph 6.

${ }^{8}$ The threshold price is an inflation-adjusted amount that begins slightly below $\$ 11$ per ton of $\mathrm{CO}_{2}$ (in 2005 U.S. dollars) and increases by 2 percent per year in real terms.
} 


\subsubsection{The EU ETS as an Example of a Multilateral Two-way Linkage}

The European Commission has determined some aspects of the design of the EU ETS, such as the sectors that are covered by the system, but the Member States have significant autonomy and responsibility with respect to many other aspects of the system within their jurisdiction, including: determining how many allowances to allocate; determining how to allocate allowances; and overseeing the monitoring, verification, and reporting of emissions. Thus, the EU ETS can be viewed as a multilateral linkage among the Member States' own systems, where a central authority enforces the harmonization of certain characteristics of each system, and where allowances issued by any Member State are recognized by all other Member States.

\section{Implications of Linking}

Linking tradable permit systems leads to diverse effects that need to be considered in assessing the merits of particular linkages, as well as the merits of linkage as a major design element of the de jure or de facto post-2012 international policy architecture. These effects depend on the type of linkage established and characteristics of the linked systems.

\subsection{Benefits of Linkage}

The most significant benefit of linking is the opportunity to lower the costs of achieving emission reduction goals by shifting reductions among linked system in a manner that minimizes total emission reduction costs. A second benefit is that linking broadens the market for allowances and credits, thereby improving market liquidity, reducing price volatility, and lessening market power concerns. If one or both of the linked systems is small, these benefits can be very important. ${ }^{10} \mathrm{~A}$ third benefit of linking is that it offers the opportunity for nations to establish "common but differentiated responsibilities," consistent with the United Nations Framework Convention on Climate Change (United Nations 1992), without increasing the cost of achieving global emission targets. That is, as long as two systems are linked, they can cost-effectively achieve a particular collective emissions target regardless of how emission reduction responsibilities are initially allocated across those countries. These attributes of linking are likely to make it an important element of any cost-effective, long-run effort to reduce GHG emissions in which tradable permit systems feature prominently.

Under certain circumstances, linking can also decrease global emissions by reducing emissions leakage. For example, linkage between a cap-and-trade system and a credit system reduces the cap-andtrade system's allowance price, and therefore decreases emissions leakage from that system. In some cases, this benefit may be substantial. For example, leakage is a serious concern in the RGGI system

\footnotetext{
${ }^{9}$ In his paper for the Harvard Project on International Climate Agreements, Denny Ellerman makes this point, as well as a broader one, namely that the EU ETS provides a range of valuable lessons for the development of the post-2012 international policy architecture. In addition to the linkages among EU Member States, two-way linkages were recently established between the EU ETS and Norway's emissions trading system, and between the EU ETS and systems in Iceland and Liechtenstein (Ellerman 2008).

${ }^{10}$ Of course, linking also exposes participants to new sources of price volatility from other linked systems (McKibben and Wilcoxen, 2007).
} 
in the northeastern United States: analyses have found that nearly half of the projected emission reductions at covered plants could be offset by leakage (RGGI 2007b). Thus, by reducing leakage from the RGGI system, a link between that system and a credit system could reduce global emissions by limiting leakage from the RGGI system.

\subsection{Concerns About Linkage}

While linking may reduce global emissions in some circumstances, a potential concern about linking is that - under other circumstances - it could increase global emissions. For example, any cap-and-trade system that establishes a one-way linkage with a credit system must confront the problem of "additionality": some emission reduction credits offered by a credit system may not represent truly additional emissions reductions because of the difficulty of establishing a baseline against which reductions can be measured. A considerable amount of research on credit systems, such as the CDM, has focused on this problem. ${ }^{11}$ Also, although linking can reduce overall emissions leakage under certain circumstances, its effects on prices can increase leakage under other circumstances.

In some cases, the distributional implications of a link may be a source of concern. Just as international trade changes the prices faced by producers and consumers in different nations, allowance trading across systems raises allowance prices in one of the linked systems and reduces prices in the other system. Hence, while yielding overall cost savings, linking can create both winners and losers. Impacts on any participant firm depend on changes in the allowance price that the firm faces, and on whether that firm is a net allowance buyer or seller. Also, because changes in allowance prices affect the prices of energy and other emissions-intensive goods, linkage can also have significant effects on firms and households that do not directly participate in trading. Likewise, by changing the production costs of firms that are emissions-intensive or that rely on emissions-intensive inputs, linkage can have significant effects on competitiveness.

The inter-system allowance trading resulting from linkage leads to capital flows between countries. Because any trading is voluntary, these capital flows necessarily are beneficial to the entities involved in the trading, but others may object to some of these potentially large capital flows (Bradsher 2007; Summers 2007). This has not been a problem in the EU ETS (Ellerman 2008), although to-date, the capital flows within the EU ETS have been relatively small.

An additional concern related to linkage is that it can reduce national control over the design and impacts of a domestic tradable permit system. Once a system establishes links, its allowance price and emissions consequences are influenced by developments in the linked system(s), including possibly decisions made by the government(s) overseeing the linked system(s). The degree to which linking reduces a country's control over its domestic system can depend in part on the relative size of the linked systems. While the post-link allowance price in linked systems will be between their pre-link prices, it will tend to be closer to the larger system's pre-link price. For example, prior to linking with the EU ETS, Norway was able to influence the allowance price in its system through its decisions about how many allowances to issue and what sources to include under its cap. Yet, given the size of Norway's

\footnotetext{
${ }^{11}$ See the papers prepared for the Harvard Project on International Climate Agreements by: Keeler and Thompson; Teng and Chen; Plantinga and Richards; Cao; Kejun; Pizer, Hall, and Ueno; Shukla; Somanathan; and Victor.
} 
system compared with that of the EU ETS, once the link was established, Norway's decisions ceased to have much impact on the allowance price that participants in its system face. ${ }^{12}$

Although linking can reduce a government's control over its tradable permit system's impacts, that control already may be limited by connections with other systems through trade in emissions intensive products. The extent of such influences depends, among other factors, on the ease with which emissions generating activity can shift between systems in response to differences between them. For example, if the European Union's Member States had pursued separate, unlinked cap-and-trade systems instead of creating the EU ETS, those systems nonetheless would have had a significant influence on one another as a result of competition in emissions intensive product markets within Europe. In contrast, if cap and trade systems are established in Australia and the United States, absent a direct or indirect link between them, these systems likely would have very little influence on one another. In such a case, the implications of linking for the control that each government has over its own system would be more important.

A final concern about linkage is that it can alter the incentives that countries face with respect to setting their future caps (Helm 2003; Holtsmark and Sommervoll 2008). In particular, by changing allowance prices in each of the linked systems, a linkage alters the tradeoff that a government faces between the value it can create by issuing additional allowances, and the marginal environmental damage that arises from issuing additional allowances. Moreover, by expanding the scope of the allowance market, linkages reduce the impact that the issuance of additional allowances has on allowance prices, and therefore on the value of existing allowances.

Of course, the issue of linkage reducing control over one's domestic trading system is simply a specific case of a general consequence of a nation opening itself to international trade of any kind. The only way that a country can maintain complete control over the price of any good it produces is to isolate itself from the world economy, trading off increased control for decreased economic welfare.

\subsection{Implications of Different Types of Linkages}

The degree of control that a government can retain over its system depends in part on whether linkage is one-way or two-way. Two-way linkages can increase or decrease domestic allowance prices. Also, two-way linkages lead to complete propagation of cost containment measures across the linked systems, including safety valves and banking and borrowing provisions. In contrast, one-way linkages can only decrease the price of allowances in the system that establishes the link. Likewise, one-way linkages will only lead to propagation of cost containment measures in one direction - from the system with which a link is established to the system that establishes the link.

The effects of a linkage also depend on whether it connects two cap-and-trade systems or a capand-trade system and an emission-reduction-credit system. For example, linkage that involves an emission-reduction-credit system raises the issue of additionality. On the other hand, a link between two cap-and-trade systems can raise other concerns that may be less significant in a link with a credit

\footnotetext{
${ }^{12}$ At the same time, some elements of a cap-and-trade system's design can have substantial effects on a linked system even if the former system is significantly smaller than the latter system. One such example is a safety valve.
} 
system. For example, the increase in allowance prices in one of two linked cap-and-trade systems may have more far-reaching economic consequences — such as by increasing domestic energy prices than would the increase in credit prices resulting from a link between a cap-and-trade system and credit system.

Even though (unconstrained) two-way linkages are more certain to equilibrate international allowance prices, one-way links between cap-and-trade systems and a common (credit or cap-and-trade) system can achieve some and perhaps much of the cost savings and risk diversification that could be achieved by establishing direct two-way links among all of the cap-and-trade systems. In fact, if the common system has a sufficient supply of credits or allowances at a price below the least stringent capand-trade system's allowance price, one-way links between cap-and-trade systems and that common system can cause allowance prices of all of the linked systems to converge.

\section{The Potential Role of Linkage in International Climate Policy Architecture}

The potential role of linkage is limited by political and institutional factors. In particular, establishing direct linkages between cap-and-trade systems may require mutual recognition of emission targets, harmonization of certain design elements, and agreement on procedures for making future adjustments to the linked systems, including setting future emission caps. Therefore, in the near-term, some direct links will be less attractive and more difficult to establish than others. However, direct linkages between cap-and-trade systems and a common emission-reduction-credit system - and the indirect linkages among cap-and-trade systems that would result - may achieve some, and perhaps much, of the cost savings and other advantages of direct links among cap-and-trade systems. As a result, indirect linkages via an emission-reduction-credit system such as the CDM could become an important part of the near-term international climate policy architecture.

\subsection{Near Term Role}

Links among existing tradable permit systems are already part of the international policy architecture to address global climate change. Moreover, new connections among existing and emerging tradable permit systems will undoubtedly be established in the future.

Pairs or groups of nations, particularly those which are important trading partners, will likely establish direct two-way links between their respective cap-and-trade systems. For example, Norway, Iceland, and Liechtenstein have agreed to link their cap-and-trade systems with the EU ETS (Ellerman 2008). However, for the reasons discussed above, it may take more time to establish direct links between some cap-and-trade systems. At the same time, many of these cap-and-trade systems may nonetheless become indirectly linked through direct links with a common credit system, such as the $\mathrm{CDM}$ or some alternative, future protocol for emissions reduction credits in developing countries.

These direct and indirect linkages are currently serving as key operational elements of the existing global climate policy architecture and may become increasingly important in the future. In this sense, linkage is emerging from the bottom up as a core element of the de facto international policy architecture, which may carry beyond the end of the first commitment period of the Kyoto Protocol in 2012. 
An important feature of such anticipated near-term linkage is that most cap-and-trade systems may be connected with one another only through indirect links via a common emission-reduction-credit system. As a result, the presence of cost-containment mechanisms in one system will only affect allowance prices in other systems via the effect of those mechanisms on competition among cap-andtrade systems for credits from the emission-reduction-credit system. That is, such indirect linkages will not lead to the propagation of cost-containment mechanisms that can occur through explicit sales of allowances among directly linked cap-and-trade systems.

Although a near-term web of mostly indirect links may not result in a fully cost-effective global market for GHG emission reductions, particularly in the near-term, these indirect links may still yield much of the cost savings and other advantages of a comprehensive system of direct linkages. Moreover, these indirect links will not require the same degree of harmonization of cap-and-trade design elements as would direct links. However, the efficacy of this scenario depends heavily on widespread acceptance and effectiveness of an international credit system such as the CDM. ${ }^{13}$

An international architecture consisting solely of linkages would not guarantee broad participation, but as we explore below in section 7.2, some forms of linkage may induce participation, encourage compliance, and even lead to more stringent commitments.

\subsection{Long Term Role}

It is possible that a comprehensive set of linkages, combined with unilateral emissions reduction commitments by many nations, could function as a stand-alone climate architecture. Such a bottom-up architecture could emerge as more countries establish national cap-and-trade systems and begin to seek the gains from linking with other systems. These countries also might use the prospect of linkages as a means of providing incentives to developing countries to participate in an international agreement.

A second possibility is that a collection of bottom-up linkages might serve as a natural starting point in negotiations leading to a top-down agreement. An existing system of linkages may help to develop the experience and mutual trust necessary for global negotiations to succeed. Furthermore, as we discuss below, any future agreement is likely to be heavily influenced by the status quo system of existing linkages and institutional investments.

A third possibility — not mutually exclusive with the second - is that linkage could become an element of a larger global policy architecture. Because the trade-related cost savings available to linked systems will grow as countries adopt increasingly stringent targets, there are strong economic reasons for policy makers to favor linking. Thus, a future global architecture could incorporate a set direct links among domestic cap-and-trade systems as a key design element.

\footnotetext{
${ }^{13}$ For further discussion of critical issues associated with credit systems, we refer readers to other papers of the Harvard Project on International Climate Agreements, including: Agarwala 2008; Teng and Chen 2008; Cao 2008; Kejun 2008; Pizer, Hall, and Euno 2008; Shukla 2008; Somanathan 2008; and Victor 2008.
} 


\section{Evaluation of the Role of Linkage in International Policy Architecture}

We assess three ways in which linkage can contribute to future climate policy architecture: as an independent, bottom-up architecture; as a transition to a top down architecture; and as an element of a larger climate agreement. Our assessment is both positive and normative, as we identify the likely outcomes in each case, and evaluate these outcomes based on a set of normative criteria.

\subsection{Linkage as a Bottom-up International Policy Architecture}

Bilateral linkages are likely to continue to evolve among national and regional cap-and-trade systems and the CDM (or its successor). Could such a set of linkages, established without central coordination, function as an effective, stand-alone bottom-up international policy architecture?

Although such an architecture would need to include certain other design elements, including emissions reduction commitments and participation incentives, its distinguishing feature would be that it would grow organically from direct and indirect linkages. Indeed, if international negotiations for a successor to the Kyoto Protocol were unsuccessful, then a set of bilateral linkages could well become the de facto post-2012 architecture. We assess this architecture in terms of its likely (1) environmental performance, (2) cost effectiveness, and (3) distributional equity.

The degree to which a system of bottom-up linkages could satisfy our first criterion of meaningful environmental performance depends on whether: (a) participants set sufficient environmental targets; (b) a sufficient number of key countries participate; and (c) participants comply.

With regard to whether participants will set meaningful environmental targets, commitments to reduce emissions in an architecture of bottom-up linkages would result from unilateral decisions by individual nations, or from negotiations among small groups of nations. In developed countries, internal political support would probably be the driving force behind adoption of more stringent emission caps (Keohane and Raustiala 2008), whereas in developing nations, adoption of emissions caps could depend upon incentives provided by committed developed countries.

As described above, direct linkages between cap-and-trade systems can affect the incentives that countries face in setting their future caps. To address the possibility that linking may create incentives for some countries to adopt less stringent future caps, countries could negotiate cap trajectories as a condition for linking (Flachsland et al. 2008). On the other hand, a system of linkages has the advantage that cost savings from links may allow some countries to adopt more aggressive targets than they otherwise would.

With respect to whether an architecture of bottom-up linkages would generate participation from a sufficient number of key countries, industrialized country participation is likely to be high. As emphasized above, many countries and regions have begun to move toward setting up meaningful cap-and-trade systems and some links have already been established. On the other hand, participation by developing countries will most likely be conditional on participation incentives provided by industrialized countries. 
Positive participation incentives ("carrots") could take at least three forms. One is access to demand for the emissions credits that a developing country could produce. In fact, the CDM provides such incentives. The second is the potential gain from becoming a net seller of allowances. The third is side payments in the form of technical or development assistance. In contrast, negative participation incentives ("sticks") could take two forms. First, industrialized countries could establish border carbon taxes and/or import allowance requirements (Frankel 2008; Houser et al. 2008; Stavins 2008). Second, access to international markets for permits could be conditioned on participation and graduation. No matter what incentives are considered, however, a bottom-up system on its own may not provide the institutional structure necessary to coordinate such participation incentives.

With respect to whether participants would be likely to comply in an architecture of bottom-up linkage, the picture is no worse - and perhaps better than - for some top-down, centralized architectures. In contrast to the Kyoto approach, which leaves the implementation of international targets up to each member state, a bottom-up system would include industrialized nations where domestic institutions are sufficient to enforce compliance. It would also include developing nations where international carrots and sticks, such as revenue from permit sales and the threat of loss of access to markets for emissions credits, outweigh the costs of participating. As a result, an advantage of a bottom-up system of linkages, compared with a top-down system, is that it provides no incentive for countries to make commitments they do not intend to achieve. ${ }^{14}$

The second major criterion by which we can assess an architecture of bottom-up linkage is cost-effectiveness. This is straightforward. Because links among cap-and-trade systems create gains from trade for the participanting countries, such an architecture has the potential to be cost-effective, in that it can allow countries to achieve their collective emission targets at minimum cost. This would be the case if the bottom-up system of linkages includes a sufficient set of direct two-way links, or if that system of linkages relies primarily on indirect links through a common credit system that has an adequate supply of low-cost credits to bring about allowance price convergence.

A third important criterion is distributional equity. As was described above, linkages can create both winners and losers within each of the linked systems, and will bring about capital flows among linked systems. The political implications of these distributional effects are not obvious. First, the distributional implications of linkages will depend in part on how individual countries choose to allocate allowances in their own cap-and-trade systems. Also, while the political will to participate in a system of linkages will depend in part on the distribution of costs and benefits, it is unclear whether individual political systems will give greater weight to costs and benefits that are concentrated in particular industries or distributed broadly across an entire economy.

A bottom-up system of linkage is already evolving, and could function well in the near-term in the absence of a top-down post-2012 international policy architecture. However, for a bottom-up system to achieve meaningful long-term environmental performance, it will require the major emitters — the United States, the European Union, Russia, Japan, China, India, and other key countries — to

\footnotetext{
${ }^{14}$ To ensure compliance, a bottom-up system of linkages would need all trading partners to have comparably effective internal monitoring, reporting, and enforcement mechanisms. Harmonization of such measures is likely to occur during the negotiation of the terms of direct linkages.
} 
reach an agreement regarding emissions targets and incentives for participation. Without the cooperation of these countries, it is unlikely that global greenhouse gas emissions could be reduced by enough to prevent major climate change. Of course, if such cooperation were possible in the context of a bottom-up system, then it would presumably also be possible within a top-down system.

\subsection{Bottom-up Linkage as a Step Towards a Top-down Architecture}

A collection of linkages among cap-and-trade and emission-reduction-credit systems could serve as the foundation for a top-down climate agreement Indeed, a bottom-up system could evolve into a coherent top-down climate architecture, much as the General Agreement on Tariffs and Trade paved the way for the World Trade Organization (Carraro 2007). Questions of interest include whether such a decentralized system of linkages might create momentum towards a top-down agreement, and how existing linkages would then affect any resulting negotiated arrangement.

Any pre-existing direct or indirect links are likely to influence the evolution of a new top-down international agreement, because existing links will function as the status-quo framework. Because linkage creates winners and losers, some constituencies will resist changes, while others may welcome them. Changing the economic, organizational, and political infrastructure that facilitates existing linkages would be time-consuming and costly. More broadly, the existing system is a natural starting point for negotiations. Of course, bias towards the status quo caused by institutional inertia could also impair good decision making and impede negotiations, particularly if the existing system of links includes features that are undesirable from the standpoint of reaching a broader climate agreement. This very flaw may also be an advantage, however, for political reasons, because nations may be more willing to make commitments to a system in which they already participate. ${ }^{15}$

An existing set of links will also have implications for participation in a future international agreement. In particular, links will create constituencies within some developing countries that favor an international agreement if continued demand for credits is conditioned on movement toward such an international agreement. If these stakeholders are influential within their own countries, then linkage can foster incentives for countries to participate in a future international agreement.

Linkage may also encourage participation in a future international agreement by simplifying the negotiation process. One of the great challenges of international climate negotiations is the necessity of achieving agreement among many parties with exceptionally diverse interests. Linkages can help to mitigate this problem by creating natural negotiating blocks of nations with similar interests. The negotiations necessary to establish bilateral links can contribute to subsequent negotiation of an international agreement.

There is another way in which linkage can induce participation in a broader international, if not global, regime. ${ }^{16}$ Consider a "leader nation," which can accomplish very little to solve the global

\footnotetext{
${ }^{15}$ Another way in which existing links may influence a future climate agreement is by providing a series of experiments to test different approaches (Hahn 1998). Victor et al. (2005) argue that such as "Madisonian" approach could provide future climate negotiations with valuable insights about what features of linked trading systems do and do not work.

${ }^{16}$ We are grateful to Denny Ellerman for this point and for much of the discussion that follows.
} 
problem of climate change were it to act on its own. Linkage provides a mechanism by which that nation's emission reduction activities can be extended more widely. Although shunning, shaming, or punishing non-participant nations is one potential route to trying to broaden the coalition (Keohane and Raustiala 2008), linkage could offer another route.

This is illustrated by the evolution of certain provisions of the EU ETS. The system places "supplementarity" constraints on imports of credits from the CDM, and allows for mutual recognition of other cap-and-trade systems established by Kyoto signatories. Amendments proposed in January 2008 introduce two key changes (Ellerman 2008). First, the ability of EU ETS participants to import credits after 2012 would be contingent on there being a post-2012 international agreement, leaving the door open for some form of graduation requirement. Second, mutual recognition provisions would no longer require signature of the Kyoto Protocol, but simply the presence of a mandatory cap on emissions in the linked jurisdiction. Thus, while the CDM route is made conditional on future agreements, full mutual recognition would be opened up for any cap-and-trade system. In other words, market access is being used to induce participation, and to foster a broader system. Linkage is being used by "the leader" to induce participation in the global regime.

Linkage can also encourage compliance with a future international agreement. This could occur in two ways. First, the "Madisonian workshop" created by many uncoordinated links could provide policy experience with mechanisms for encouraging compliance (Victor et al. 2005). Second, existing links might allow countries to demonstrate good faith commitments to emissions reductions.

Linking may even lead to more stringent environmental commitments. By reducing the cost of emissions reductions, linkage may allow key industrialized countries to make greater emissions reduction commitments than they would have in the absence of linking. Linkage may reduce domestic opposition to reductions in emissions caps as the allowance price impact associated with such reductions would be mitigated by linkages.

\subsection{Bottom-up Linkage as an Element of an International Architecture}

Linkage could play a significant role as a component of a larger international climate policy architecture - a role that would not conflict with the potential near-term role of linkage as the basis for a future agreement. Since not all links function in the same way, an international policy architecture could be developed with different near-term and long-term linkage components. For example, in the near-term, a system of indirect linkages via a common credit system would provide important cost savings, while minimizing negative distributional effects and preserving a high degree of national control over allowance markets. In the longer term, the system could transition to negotiated multilateral two-way linkages that would create a single, comprehensive market for allowances and credits.

\section{How Will Near term Climate Negotiations Affect Bottom-up Linkages?}

If the emergence of a system of linkages would be beneficial to a future (bottom-up or top-down) climate agreement, then it is important to address two questions. What policy elements of a future international climate agreement will facilitate bottom-up linkages? And what policy elements would inhibit or impede such linkage? 
A post-2012 international climate agreement could include several elements that would facilitate future linkages among cap-and-trade and emission-reduction-credit systems. First, the agreement could establish an agreed trajectory of emissions caps or allowance prices. Second, it could specify a harmonized set of cost-containment measures, including offset, banking and borrowing, and safety-valve provisions. Third, it could specify a process for making future adjustments to the level of the emissions cap and other key design elements (Jaffe and Stavins 2007). Fourth, it could create an international clearinghouse for transaction records and allowance auctions (Edenhofer et al. 2007). Fifth, it could provide for the on-going operation of the CDM or a successor, which could play a central role in indirectly linking existing and emerging tradable permit systems. Sixth and finally, a post-2012 international climate agreement could help build capacity in developing countries that would permit and encourage their fuller participation through a system of bottom-up linkage. All of these features would simplify and facilitate the linkage negotiation process. ${ }^{17}$

There are also potential design elements that would best be avoided by a post-2012 agreement if it seeks to encourage linkage among tradable permit systems. Any global agreement that encourages strategic behavior could impede the development of linkages. For example, an agreement that conditions future commitments on countries' emissions levels over the coming years could undermine the ability of linkages to achieve a cost-effective distribution of emission reductions across linked systems. Also, depending on the stringency of such restrictions, an international agreement that imposes "supplementarity" restrictions — in which countries must achieve some specified percentage of emissions reductions on their own, without trading — will severely limit the potential benefits of linkage by curtailing the amount of international trading that can occur.

\section{Conclusions}

Cap-and-trade systems are emerging as a preferred domestic instrument for reducing emissions of greenhouse gases in many parts of the world, and the Clean Development Mechanism has developed a substantial constituency, despite some concerns about its performance. Because of the considerable political and economic pressure to link these systems, linkage may be expected to play a de facto, if not de jure, role in any future international climate policy architecture.

In the near-term, linkage will continue to grow in importance as a core element of a bottom-up, de facto international policy architecture. The EU ETS has already established direct links with systems in neighboring countries, and the CDM has emerged as a potential hub for indirect links among cap-and-trade systems worldwide. As new cap-and-trade systems appear in countries such as Australia, Canada, and the United States, the global network of direct and indirect links will likely continue to spread.

In the longer term, linkage could play a variety of roles. One possibility is that a set of linkages, combined with unilateral emissions reduction commitments by many nations, could function as a stand-alone climate architecture. Such a system would be cost-effective as long as it included a sufficient

\footnotetext{
${ }^{17}$ Some of these elements could also emerge without a post-2012 multi-national climate agreement, but instead through specific bilateral links among systems.
} 
number of direct two-way links or indirect links through a common international credit system with an adequate depth of low-cost credits. However, it may be difficult for a system of bottom-up linkages to achieve meaningful long-term environmental performance, primarily because it would lack a coordinating mechanism to encourage widespread participation.

A second long-term possibility is that a collection of bottom-up links may eventually evolve into a comprehensive, top-down agreement. In the near-term, a system of direct and indirect linkages would build institutional capacity and provide important cost savings, and in the longer term, the system would serve as a natural starting point in negotiations leading to a top-down agreement.

A third long-term possibility (which is entirely compatible with the second possibility) is that linkage could play a significant role as a component of a larger international climate policy agreement. Such an architecture would use linkage to provide a number of important benefits, reducing the overall costs of meeting emissions reduction targets, improving market liquidity, and providing a framework for the implementation of "common but differentiated responsibilities."

Despite the clear benefits of linkage, there are also legitimate concerns about the implications of some linkages. These concerns depend, in part, on the type of linkage involved. Two-way direct links among cap-and-trade systems reduce the control that the linking countries have over their domestic allowance prices and emissions. Two-way links also result in the complete and automatic propagation of cost-containment measures from one system to the other. On the other hand, indirect links present a different set of concerns. In particular, indirect linkage via a common credit system could adversely affect global emissions if additionality problems in the credit system are severe. The interim performance of the CDM suggests that this concern deserves serious attention.

Thus, there is a glaring trade-off between direct linkages, which can require a high degree of harmonization and international cooperation, and indirect linkages via a common credit system, which raise concerns about additionality. This tradeoff may suggest a natural progression. In the near-term, indirect linkage of cap-and-trade systems via a common credit system (such as the CDM) could achieve some of the cost savings and risk diversification of direct linkage, but without the need for as much harmonization of emerging and existing cap-and-trade systems. Such indirect linkage would also limit potential distributional concerns and preserve a high degree of national control over allowance markets. In the longer term, international negotiations could establish shared expectations about environmental targets and emission reduction responsibilities that would serve as the basis for a broad set of multilateral, direct links among cap-and-trade systems. This progression could promote the near-term goals of participation and cost-effectiveness, while helping to build the foundation for a more comprehensive future agreement. 


\section{REFERENCES}

ABC News. 2008. "Japan PM Announces Plan to Cut Emissions." June 9. http://www.abc.net.au/news/stories/2008/06/09/2269404.htm

Agarwala, Ramgopal. 2008. “Towards a Global Compact for Managing Climate Change.” Paper prepared for the Harvard Project on International Climate Agreements.

Australian Government. 2008. "Carbon Pollution Reduction Scheme Green Paper.” Department of Climate Change. Canberra, July.

Australian Prime Ministerial Task Group on Emissions Trading. 2007. "Report of the Task Group on Emissions Trading." Barton, Australia: Department of the Prime Minister.

Baron, Richard, and Stephen Bygrave. 2002. "Towards International Emissions Trading: Design Implications for Linkages." Paris, France: Organization for Economic Co-operation and Development and International Energy Agency. COM/ENV/EPOC/IEA/SLT(2002)5.

Baron, Richard, and Cédric Philibert. 2005. Act Locally, Trade Globally: Emissions Trading for Climate Policy. Paris, France: OECD and IEA.

Blyth, William and Martina Bosi. 2004. "Linking Non-EU Domestic Emissions Trading Schemes with the EU Emissions Trading Scheme.” Paris, France: OECD and IEA.

Bradsher, Keith. 2007. “Clean Power That Reaps a Whirlwind.” New York Times, May 9.

BusinessGreen. 2008. "Japan to launch cap-and-trade trial in October." July 30, 2008. http://www.businessgreen.com/business-green/news/2222816/japan-launch-cap-trade-trial

California Air Resources Board. 2008. "Climate Change Draft Scoping Plan: A Framework for Change." June.

Cao, Jing. 2008. "China's Perspective on International Climate Policy." Paper prepared for the Harvard Project on International Climate Agreements.

Carbonpositive. 2007. “CER Prices Rise See Modest Gains.” October 24.

Carraro, Carlo. 2007. "Incentives and Institutions: A Bottom-Up Approach to Climate Policy." In Architectures for Agreement, Joe A. Aldy and Robert N. Stavins, eds. Cambridge University Press.

Edenhofer, Ottmar, Christian Flachsland, and Robert Marschinski. 2007. "Towards a Global $\mathrm{CO}_{2}$ Market: An Economic Analysis." Potsdam Institute for Climate Impact Research.

Ellerman, Denny. 2008. “The EU's Emissions Trading Scheme: Prototype of a Global System?” Paper prepared for the Harvard Project on International Climate Agreements. 
Ellis, Jane, and Dennis Tirpak. 2006. "Linking GHG Emission Trading Schemes and Markets." Paris, France: OECD and IEA. COM/ENV/EPOC/IEA/SLT(2006)6.

Environment Canada. 2008. "Turning the Corner: Regulatory Framework for Industrial Greenhouse Gas Emissions.” www.ec.gc.ca/doc/virage-corner/2008-03/pdf/541_eng.pdf.

Euractiv.com. 2007. "Norway to Join EU Carbon-Trading Scheme.” March 9.

European Commission. 2004. "Directive 2004/101/EC of the European Parliament and of the Council Amending Directive 2003/87/EC Establishing a Scheme for Greenhouse Gas Emission Allowance Trading within the Community, in respect of the Kyoto Protocol's Project Mechanisms." Official Journal of the European Union. L 338/18 L 338/23. November 13.

European Commission. 2005. "EU Action Against Climate Change: EU Emissions Trading - An Open Scheme Promoting Global Innovation.” Brussels, Belgium.

European Commission. 2007a. "Commission Decision of August 31, 2007 Concerning the National Allocation Plan for the Allocation of Greenhouse Gas Emission Allowances Notified by Denmark in Accordance with Directive 2003/87/EC of the European Parliament and of the Council." Brussels, Belgium.

European Commission. 2007b. "Emissions Trading: EU Wide Cap for 20082012 Set at 2.08 Billion Allowances after Assessment of National Plans for Bulgaria." Brussels, Belgium: October 26.

European Commission. 2008. "Proposal for a Directive of the European Parliament and of the Council Amending Directive 2003/87 / EC So As To Improve and Extend the Greenhouse Gas Emission Allowance Trading System of the Community.” Brussels, Belgium: January 23.

Flachsland, Christian, Ottmar Edenhofer, Michael Jakob, and Jan Steckel. 2008. "Developing the International carbon Market: Linking Options for the EU ETS.” Report to the Policy Planning Staff in the Federal Foreign Office, Potsdam Institute for Climate Impact Research.

Frankel, Jeffrey. 2008. "Formulas for International Climate Policy." Paper prepared for the Harvard Project on International Climate Agreements.

Hahn, Robert W. 1984. "Market Power and Transferable Property Rights." Quarterly Journal of Economics 99(4): 753-765.

Hahn, Robert W. 1998. The Economics and Politics of Climate Change. American Enterprise Institute Press: Washington, D.C.

Haites, Erik and Fiona Mullins. 2001. "Linking Domestic and Industry Greenhouse Gas Emission Trading Systems.” Toronto: Margaree Consultants Inc.

Helm, Carsten. 2003. "International Emissions Trading with Endogenous Allowance Choices.” Journal of Public Economics 87(12): 2737-2747. 
Holtsmark, Bjart J., and Dag Einar Sommervoll. 2008. "International Emissions Trading in a Non-cooperative Equilibrium.” Statistics Norway, Research Department, Discussion Paper No. 542, May 2008.

Houser, Trevor, Rob Bradley, Britt Childs, Jacob Werksman, and Robert Heilmayr. 2008. Leveling the Carbon Playing Field: International Competition and US Climate Policy Design. Peterson Institute.

Jaffe, Judson, and Robert Stavins. 2007. "Linking Tradable Permit systems for Greenhouse Gas Emissions: Opportunities, Implications, and Challenges.” IETA Report on Linking GHG Emissions Trading Systems. Prepared for the International Emissions Trading Association. November.

Japanese Ministry of the Environment. 2006. "FY 2004 Greenhouse Gas Emissions in Japan.” Tokyo, Japan: May 25.

Kejun, Jiang. 2008. "Opportunities for Developing Country Participation in an International Climate Change Policy Regime." Paper prepared for the Harvard Project on International Climate Agreements.

Keohane, Robert, and Kal Raustiala. 2008. "Promoting Compliance in International Climate Policy Agreements." Paper prepared for the Harvard Project on International Climate Agreements.

Kruger, Joseph, Wallace Oates, and William Pizer. 2007. "Decentralization in the EU Emissions Trading Scheme and Lessons for Global Policy." Review of Environmental Economics and Policy 1(1): $112-133$

McKibbin, Warwick J., and Peter J. Wilcoxen. 2007. "A credible foundation for long-term international cooperation on climate change." In Architectures for Agreement, Joe A. Aldy and Robert N. Stavins, eds. Cambridge University Press.

Michaelowa, Axel and Frank Jotzo. 2005. “Transaction Costs, Institutional Rigidities and the Size of the Clean Development Mechanism.” Energy Policy 33(4): 511- 523.

National Emissions Trading Taskforce. 2006. "Possible Design for a National Greenhouse Gas Emissions Trading Scheme."

Nigoff, Mindy. 2006. "Clean Development Mechanism: Does the Current Structure Facilitate Kyoto Protocol Compliance?” Georgetown International Environmental Law Review 18(2): 249-276.

Norwegian Ministry of the Environment. 2005. "Norway's Report on Demonstrable Progress under the Kyoto Protocol: Status Report as of December 2005.” Oslo, Norway.

Pizer, William, Daniel Hall, and Takahiro Euno. 2008. "Developing Country Commitments.” Paper prepared for the Harvard Project on International Climate Agreements.

Pointcarbon.com. 2007. "JI Update: 12 Projects Submitted to UN in October." November 1. 
Regional Greenhouse Gas Initiative (RGGI). 2007a. "Model Rule.” January 5, 2007 version.

Regional Greenhouse Gas Initiative (RGGI). 2007b. "IPM Energy Modeling Documents.”

Shukla, P.R. 2008. "Development and Climate Change: an Indian Perspective." Paper prepared for the Harvard Project on International Climate Agreements.

Somanathan, E. 2008. "Development and Climate Change." Paper prepared for the Harvard Project on International Climate Agreements.

Stavins, Robert N. 1995. “Transaction Costs and Tradeable Permits." Journal of Environmental Economics and Management 29(1995): 133-148.

Stavins, Robert N. 2008. "A Meaningful U.S. Cap-and-Trade System to Address Climate Change." Harvard Environmental Law Review 32(2): 293-371.

Sudo, Tomonori. 2006. "Japanese Voluntary Emissions Trading Scheme (JVETS) - Overview and Analysis." Presentation at the US-Japan Workshop on Climate Actions and Co-Benefit. March 22-23.

Summers, Lawrence. 2007. "Foreword." In Architectures for Agreement, Joe A. Aldy and Robert N. Stavins, eds. Cambridge University Press.

Tatsutani, Marika and William A. Pizer. 2008. "Managing Costs in a U.S. Greenhouse Gas Trading Program: A Workshop Summary.” Resources For the Future Discussion Paper 08-23.

Teng, Fei, and Wenying Chen. 2008. A Measurable, Reportable, and Verifiable Post 2012 Climate Framework. Paper prepared for the Harvard Project on International Climate Agreements.

United Nations. 1992. "Rio Declaration on Environment and Development." Annex 1 of the Report of the United Nations Conference on Environment and Development: Rio de Janeiro, June 3 14.

United Nations Environment Program (UNEP) Risoe Centre. 2008. "Status of JI Projects." http://www.cdmpipeline.org/ji-projects.htm\#1. Accessed August 21, 2008.

United Nations Framework Convention on Climate Change (UNFCCC). 2008. "Expected Average Annual CERs from Registered Projects by Host Country.” August 18.

Victor, David. 2008. "Development and Climate Change." Paper prepared for the Harvard Project on International Climate Agreements.

Victor, David, Joshua House, and Sarah Joy. 2005. "A Madisonian Approach to Climate Policy." Science 309(5742): 18201821. 